\title{
The Effect of E. Coli L-Asparaginase on Oral Glucose Tolerance and Insulin Release in Man
}

\author{
R. L. Lavine ${ }^{1}$, I. Brodsky ${ }^{2}$, C. D. Garofano ${ }^{1}$, and L. I. Rose ${ }^{1}$ \\ ${ }^{1}$ Department of Medicine, Division of Endocrinology and Metabolism, and ${ }^{2}$ Department of Medicine, \\ Hematology-Oncology, Hahnemann Medical College and Hospital, Philadelphia, Pennsylvania, USA
}

\begin{abstract}
Summary. To study the effect of E. Coli L-asparaginase on glucose tolerance and insulin release, 6 patients with neoplastic disease were subjected to 3 hour oral glucose tolerance tests with simultaneous measurement of serum immunoreactive insulin (IRI) levels before and following the intravenous administration of $5000 \mathrm{I}$. U. L-asparaginase/day for 4 days. Five of the patients exhibited a significant deterioration in glucose tolerance; however, no change was noted in their fasting glucose and IRI levels. The deterioration in glucose tolerance was associated with a decrease in the amount of insulin secreted in the first 30 minutes after the oral glucose load. The total amount of insulin released during the 3 hour test remained unchanged. These studies suggest that L-asparaginase can cause a deterioration of glucose tolerance without accompanying fasting hyperglycaemia. This may be due, in part, to a decrease in glucose-induced insulin release during the first thirty minutes following oral glucose.
\end{abstract}

Key words: L-asparaginase, glucose, insulin, glucose tolerance, diabetes mellitus.

During clinical trials utilising the cancer chemotherapeutic enzyme, L-asparaginase, marked hyperglycaemia associated with low circulating levels of serum immunoreactive insulin (IRI) as well as ketoacidosis has been precipitated in previously nondiabetic individuals [1-6]. Since L-asparaginase is known to impair the synthesis of other proteins such as $\beta$-lipoprotein, fibrinogen and albumin [7-9], the observed hyperglycaemia was postulated to be due to L-asparaginase inhibition of insulin biosynthesis [5]. It is possible, however, that $\mathbf{L}$-asparaginase induces hyperglycaemia by altering or blocking insulin secretion rather than inhibiting insulin biosynthesis.

Only one study has actually investigated the effects of L-asparaginase therapy on glucose tolerance. Whitecar et al [5] studied four patients before and after L-asparaginase therapy. Two of his patients developed fasting hyperglycaemia. The remaining 2 patients maintained normal fasting glucose levels and had normal intravenous glucose tolerance tests. No studies have been reported to date demonstrating abnormalities in glucose tolerance in L-asparaginase treated patients who have had normal fasting blood glucose. In the present study, 3 hour oral glucose tolerance tests with simultaneouse measurements of immunoreactive insulin levels were performed in non-diabetic patients before and after therapy with 20,000 I. U. E. Coli L-asparaginase (5000 U/day) to evaluate the effect of L-asparaginase on glucose tolerance.

\section{Methods and Materials}

Patients: Five men and one woman ranging in age from 39-71 years and having a variety of malignant tumours were studied (Table 1). Patients with a prior history of diabetes mellitus or pancreatitis were excluded from this study. The patients were scheduled to receive L-asparaginase therapy as part of the treatment for their malignant diseases. All previous medications were continued unchanged during the study. The E. ColiL-asparaginase was dissolved in $10 \mathrm{ml}$ normal saline immediately before intravenous administration and was given over a two minute period. A standard dose of $5,000 \mathrm{IU} /$ day was administered to all patients. The patients were all ambulatory and only restricted in activity when undergoing glucose tolerance tests.

\section{Glucose Tolerance Tests}

After an overnight fast and prior to L-asparaginase therapy (time 0 ), venous blood was taken for plasma 
Table 1. Patients

\begin{tabular}{|c|c|c|c|c|}
\hline Subject & Age & Sex & Diagnosis & Other medication during study \\
\hline 1 & 55 & $\mathbf{M}$ & Squamous carcinoma of lung & None \\
\hline 2 & 58 & $\mathrm{M}$ & Histiocytic lymphoma & Flurazepam hydrochloride, Acetaminophen, Milk of Magnesia \\
\hline 3 & 64 & M & $\begin{array}{l}\text { Chronic lymphocytic } \\
\text { leukaemia }\end{array}$ & None \\
\hline 4 & 52 & $\mathrm{~F}$ & Cancer of ovary & $\begin{array}{l}\text { Thyroid (dessicated), Prochlorperazine, Flurazepam hydrochloride, } \\
\text { Acetaminophen }\end{array}$ \\
\hline 5 & 71 & $\mathbf{M}$ & Histiocytic lymphoma & None \\
\hline 6 & 39 & $\mathbf{M}$ & Lymphosarcoma & Prednisone, Indomethacin, Trimethobenzamide hydrochloride \\
\hline
\end{tabular}

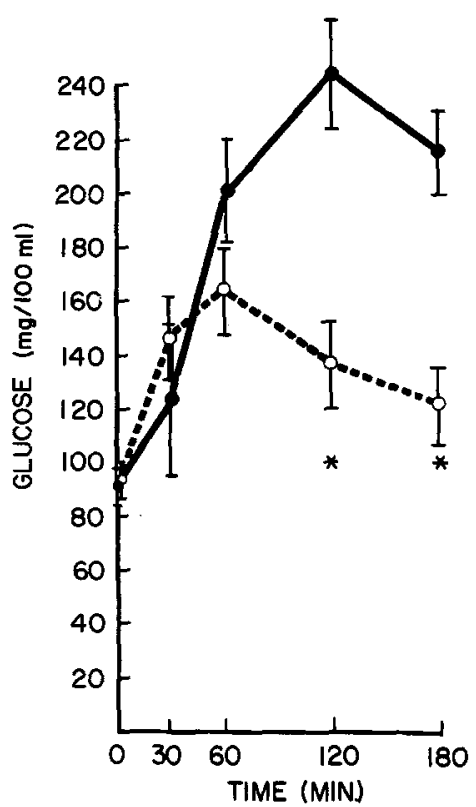

Fig. 1. The effect of 20,000 units $(5,000 \mathrm{u} / \mathrm{d} \mathrm{IV})$ of $E$. Coli $\mathrm{L}$-asparaginase on $100 \mathrm{~g}$ oral glucose tolerance in 6 patients with neoplastic diseases. Mean $\pm \mathrm{SEM}$; ${ }^{*} \mathrm{P}<0.05$; $0^{--.-\circ} \circ$ Before; $\bullet$ After

glucose [10], serum immunoreactive insulin (IRI) [11], amylase estimation and liver function tests (total protein, albumin, alkaline phosphatase, serum glutamic oxalacetic transaminase (SGOT), lactic dehydrogenase (LDH) and total bilirubin). D-glucose $(100 \mathrm{~g})$ was taken orally and blood for glucose and IRI was obtained 30, 60, 120 and 180 minutes thereafter. After the test, the patient received 5,000 IU of L-asparaginase IV daily. On the 5 th day after an overnight fast and 24 hours after the previous Lasparaginase dose, a repeat 3 hour oral glucose tolerance test was performed. The tests were started between 8:00 and 9:00 a. m. with the patient at bedrest. Fasting blood samples for plasma glucose and serum IRI were also obtained daily, prior to the daily dose of L-asparaginase.

Statistical analysis of the data was carried out utilising the paired $\mathrm{t}$-test [12].

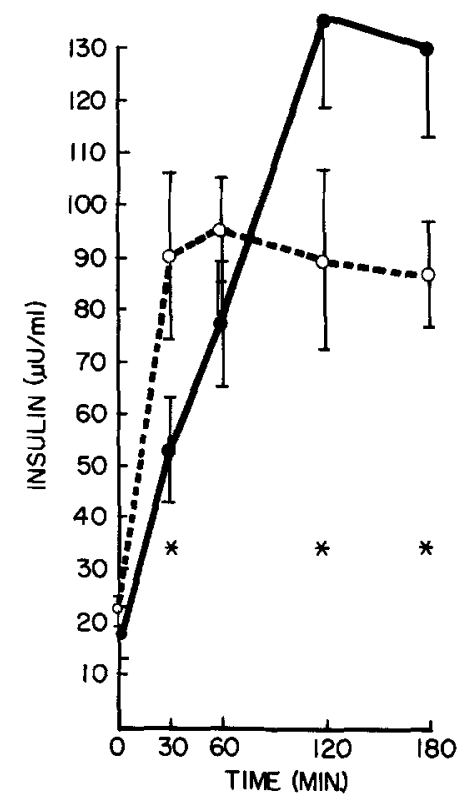

Fig. 2. The effect of 20,000 units $(5000 \mathrm{u} / \mathrm{d}$ IV) of E. Coli $\mathrm{L}$-asparaginase on insulin secretory response to $100 \mathrm{~g}$ oral glucose load in 6 patients with neoplastic diseases. Mean \pm SEM; $* \mathrm{P}<0.05$; $0_{----\circ} \circ$ Before; $\longrightarrow$ After

\section{Results}

L-asparaginase therapy produced no significant changes in the fasting plasma glucose, serum IRI or amylase levels. There was a significant fall in total protein and albumin levels. (Total protein: $6.7 \pm 0.3$ grams $/ 100 \mathrm{ml}$ before to $5.6 \pm 0.6 \mathrm{gm} / 100 \mathrm{ml}$ after (mean $\pm \mathrm{SD}$ ) albumin: $4.0 \pm 0.3 \mathrm{gm} / 100 \mathrm{ml}$ before to $3.3 \pm 0.3 \mathrm{gm} / 100 \mathrm{ml}$ after). However, no change in LDH, SGOT, alkaline phosphatase or total bilirubin was observed. The patients tolerated the drug well and specifically there was no evidence of pancreatitis, hepatitis, skin rash, anaphylaxis, anorexia, nausea and vomiting.

The effects of L-asparaginase on glucose tolerance and insulin response to oral glucose are shown in Figures 1 and 2. L-asparaginase in the dose administered in this study had little effect on fasting 
plasma glucose levels. However, the drug caused significant deterioration of glucose tolerance in 5 of the 6 patients studied (Fig. 1). L-asparaginase did not significantly affect the total insulin response to oral glucose (Fig. 2). L-asparaginase significantly decreased the IRI response at 30 minutes, but at 120 and 180 minutes the IRI response was significantly increased at a time when the plasma glucose was also significantly elevated.

In order to assess the magnitude of the changes in glucose and insulin increments during the tests were calculated (Table 2). L-asparaginase significantly increased the total 3 hour glucose increment, but not the 0-30 minute increment. L-asparaginase did not significantly alter the total insulin increment, but did decrease the 0-30 minute insulin increment.

\section{Discussion}

Use of E. Coli L-asparaginase has resulted in severe hyperglycaemia [1-6] in previously non-diabetic patients. This hyperglycaemia has been postulated to be secondary to an inhibition of insulin biosynthesis since it was associated with low insulin levels [5]. The present study, in contrast to previous reports, suggests that L-asparaginase may contribute to glucose intolerance by altering the release of insulin since these was a reduction in the insulin increment during the first 30 minutes of the glucose tolerance test despite no change in the total insulin increment during the entire 3 hours. This suggests that Lasparaginase caused a reduction in the early phase of insulin release which is critical in determining subsequent glucose tolerance $[13,14]$. This pattern is similar to that seen in some diabetic patients who release substantial amounts of insulin with glucose tolerance testing, but have a relative deficiency in the early insulin response and glucose intolerance [15]. The post-L-asparaginase glucose and insulin response curves observed in this study are quite similar in appearance to those seen in early adult onset diabetes mellitus. Although not definitely excluded, it is unlikely that the observed changes in glucose and insulin following L-asparaginase were due to $E$. Coli endotoxin which might have been present as a contaminant in the L-asparaginase preparations. The reasons for this viewpoint are:

1) E. Coli endotoxin causes severe hypoglycaemia in animals [16].

2) Hypoglycaemia has also been observed in man during septic shock [17].

3) E. Coli endotoxin in dogs has been observed to cause only transient hyperglycaemia. However, 60 minutes after endotoxin administration the animals become increasingly hypoglycaemic [18].
Table 2. Effect of E. Coli L-asparaginase on glucose and insulin responses to $100 \mathrm{~g}$ oral glucose load

\begin{tabular}{llll}
\hline Variable & Before & After & $\mathrm{p}^{\mathrm{a}}$ \\
\hline $\begin{array}{c}\text { Total glucose increment } \\
0-180 \mathrm{~min}(\mathrm{mg} / 100 \mathrm{ml})\end{array}$ & $227 \pm 43^{\mathrm{b}}$ & $422 \pm 40$ & $<0.01$ \\
$\begin{array}{c}\text { Total insulin increment } \\
\quad 0-180 \mathrm{~min}(\mu \mathrm{U} / \mathrm{ml})\end{array}$ & $273 \pm 30$ & $324 \pm 42$ & $\mathrm{NS}$ \\
$\begin{array}{c}\text { Glucose increment } \\
0-30 \text { min }(\mathrm{mg} / 100 \mathrm{ml})\end{array}$ & $55 \pm 9$ & $46 \pm 12$ & $\mathrm{NS}$ \\
$\begin{array}{c}\text { Insulin increment } \\
0-30 \mathrm{~min}(\mu \mathrm{U} / \mathrm{ml})\end{array}$ & $68 \pm 17$ & $36 \pm 7$ & $<0.05$ \\
\hline
\end{tabular}

a Before vs. after L-asparaginase therapy

b Mean $\pm \operatorname{SEM}(6$ patients)

It is also unlikely that the observed glucose intolerance and altered insulin responses after $\mathrm{L}$ asparaginase therapy are due to a resistance to insulin action caused by the drug since Whitecar et al. found their hyperglycaemic patients responsive to small amounts of exogenous insulin [5]. The observed changes in glucose tolerance are probably not secondary to pancreatitis, a known complication of L-asparaginase use $[8,19]$, since serum amylase remained unchanged and there was no clinical evidence of pancreatitis. The observed changes in glucose tolerance do not appear to be secondary to hepatic dysfunction, also a concomittant of Lasparaginase therapy $[8,19]$. While the changes in glucose tolerance and insulin response to glucose are not unlike those reported in hepatic disease [20], the present patients only had minimal chemical evidence of L-asparaginase induced hepatic dysfunction. These patients demonstrated decreased total protein and albumin levels, but no changes in total bilirubin, alkaline phosphatase, LDH and SGOT levels. Also, there was no clinical evidence of hepatic dysfunction. Many medications can affect glucose tolerance and glucose induced insulin secretion. However, the observed changes in glucose and insulin in this study were unlikely to have been due to the effect of medications other than L-asparaginase since all medications, doses and drug schedules were not altered immediately prior to or during the study.

The deterioration of glucose tolerance and altered insulin release differs from previous studies. This descrepancy might be related to differences in the dose of L-asparaginase administered and/or the duration of therapy. The average dose of Lasparaginase according to Cappizi et al. [19] ranges from $200 \mathrm{IU}$ to $1000 \mathrm{IU} / \mathrm{Kg} /$ day administered for 14 to 28 days. Our dose was $5000 \mathrm{IU} /$ day for 4 days. While not directly comparable to the doses described by Cappizi et al., our patients received less of a cumulative dose of the drug. Therefore, it is possible 
that smaller cumulative doses of L-asparaginase, such as those used in this study, alter the pattern of insulin secretion and impair glucose tolerance by depressing the early phase of insulin release while larger doses may depress total insulin release and/or biosynthesis. The possibility that the doses used in this study also resulted in defective insulin biosynthesis has not been excluded.

It is interesting that L-asparaginase depresses lymphocyte function by an effect on the lymphocyte cell membrane [21]. Perhaps the effect of Lasparaginase on glucose-stimulated insulin release is due to a similar effect on the B-cell membrane.

\section{References}

1. Faletta, J. M., Steuber, C. P., Hayes, J. W., Starling, K. A., Hill, L. L.: Non-ketotic hyperglycemia due to prednisone (NSC - 10023) following ketotic hyperglycemia due to Lasparaginase (NSC - 109229) plus prednisone. Cancer Treat. Rep. 56, 781-782 (1972)

2. Gillette, P. C., Hill, L. L., Starling, K. A., Fernbach, D. J.: Transient diabetes mellitus secondary to L-asparaginase therapy in acute leukemia. J. Pediatr. 81, 109-11 (1972)

3. Land, V. J., Sutow, W. W., Fernbach, D. J., Lane, D. M., Williams, T. E.: Toxicity of L-asparaginase in children with advanced leukemia. Cancer 30, 339-347 (1972)

4. Gailani, S., Nussbaum, A., Ohnuma, T., Freeman, A.: Diabetes in patients treated with asparaginase. Clin. Pharmacol. Ther. 12, 487-490 (1971)

5. Whitecar, J. P., Jr., Bodey, G. P., Hill, C. S., Jr., Samaan, N.: Effect of L-asparaginase on carbohydrate metabolism. Metabolism 19, 581-586 (1970)

6. Ohnuma, T., Holland, J.F., Freeman, A., Sinks, L. F.: Biochemical and pharmacological studies with $\mathrm{L}$-asparaginase in man. Cancer Res. 30, 2297-2305 (1970)

7. Haskell, C. M., Canellos, G. P., Levanthal, B. G., Carbone, P. P., Serpick, A. A., Hansen, H. H.: L-asparaginase toxicity. Cancer Res. 29, 974-975 (1969)

8. Whitecar, J. P., Jr., Bodey, G. P., Harris, J. E., Friereich, E. J.: L-asparaginase. N. Engl. J. Med. 282, 732-734 (1970)
9. Brodsky, I., Kahn, S. B., Vash, G., Ross, E. M., Petkov, G.: Fibrinogen survival with $\left({ }^{75} \mathrm{Se}\right)$ selenomethionine during Lasparaginase therapy. Br. J. Haematol. 20, 477-487 (1971)

10. Huggett, A.S. G., Dixon, D. A.: Use of glucose oxidase, peroxidase and o-dianisidine in determination of blood and urinary glucose. Lancet 1957 II, 368-371

11. Ceska, M., Grossmuller, F., Ludkvist, U.: Solid-phase radioimmunoassay. Acta Endocrinol. (Kbh.) 64, 111-125 (1970)

12. Snedecor, G. W., Cochran, W. G.: Statistical Methods, p. 97. Ames, Iowa: Iowa State College Press 1967

13. Thorell, J. I.: Effect of transient elevation of plasma insulin within physiologic levels (simulated early insulin response) on blood glucose levels. J. Clin. Endocrinol. Metab. 37, 423-430 (1973)

14. Lerner, R. L., Porte, D., Jr.: Relationships between intra-venous glucose loads, insulin responses and glucose disappearance rate. J. Clin. Endocrinol. Metab. 33, 409-417 (1971)

15. Bagdade, J. D., Bierman, E. L., Porte, D., Jr.: The significance of basal insulin levels in the evaluation of the insulin response to glucose in diabetic and non-diabetic subjects. J. Clin. Invest. 46, 1459-1557 (1967)

16. Hinshaw, L. B.: The role of glucose in endotoxin shock. Circ. Shock 3, 1-10 (1976)

17. Berk, J. L., Hagen, J. F., Beyer, W. H., Gerber, M. J.: Hypoglycemia of shock. Ann. Surg. 171, 400-412 (1970)

18. Wolfe, R. R., Elahi, D., Spitzer, J. J.: Glucose and lactate kinetics after endotoxin administration in dogs. Am. J. Physiol. 232, E180-E 185 (1977)

19. Cappizi, R. L., Bertino, J. R., Handschumacher, R. E.: LAsparaginase. Annu. Rev. Med. 21, 433-444 (1970)

20. Megyesi, C., Samols, E., Marks, V.: Glucose tolerance and diabetes in chronic liver disease. Lancet 1967 II, 1051-1054

21. Fidler, I. J., Montgomery, P. E.: Effects of L-asparaginase on lymphocyte surface and blastogenesis. Cancer Res. 32, 2400-2406 (1972)

Received: October 21, 1977,

and in revised form: April 19, 1978

Dr. R. L. Lavine

Division of Endocrinology and Metabolism

Hahnemann Medical College and Hospital

230 North Broad Street

Philadelphia, PA 19102

USA 